\title{
AYMOND, UM RUIDOSO SUCESSO: A TRAJETÓRIA DO \\ TRAVESTIDO ARGENTINO NO TEATRO DE REVISTA BRASILEIRO
}

\author{
Giovanna Zamith Cesário \\ UFRJ
}

\begin{abstract}
Resumo
Teatros fervilhavam de mentes e olhares curiosos, artistas dos mais variados tipos estrelavam na ribalta. A todo momento novas peças surgiam, companhias iam e chegavam no país. Essa era a atmosfera do teatro de revista nas décadas de 20 e 30 do século XX. E será em meio a esse cenário que Aymond, "o garganta de ouro", se tornaria um artista respeitado pelos companheiros, admirado pelo público, cobiçado pelos empresários, e sobretudo, um sopro de novidade na disputa com o crescente cinema. Através de críticas, crônicas e propagandas de jornais, esse artigo convida - leitor a conhecer a trajetória do argentino Norberto Américo Aymonino.
\end{abstract}

\section{Palavras-chave:}

Teatro de Revista; Aymond; Travestismo.

\section{DA PEQUENA DOLORES PARA BUENOS AIRES}

Filho de Pedro e Júlia Aymonino, Norberto Américo Aymonino chega ao mundo em 24 de abril de 1902. Aymond nasceu em uma cidadezinha chamada Dolores, que, segundo estudiosos do circuito artístico portenho, não apresentava relevância no meio cultural argentino. Por isso, muda-se, aproximadamente aos vinte anos, para Buenos Aires. É possível dizer que Aymond já se apresentava no teatro revisteiro argentino travestido de mulher. No começo do século $X X$, o travestimento já era algo familiar no mundo do teatro, mas ainda causava estranheza aos espectadores; essa prática chegou no Brasil no final do século XIX. O primeiro artista que supostamente se apresentou no Brasil, foi o americano John Bridges em 1896. A historiadora Neyde Veneziano (1991) chamou atenção também para o português José Ricardo, que segundo ela:
Abstract

Theaters bursted with curious minds and eyes, the most colorful and varied sort of artists lighted up the limelight. At all times new plays came out and theater companies were in and out of the country. Such was the firing atmosphere of the theatrical revue of the 20's and 30's XX century. Amongst this scenary would Aymond, the "garganta de ouro", become a well respected artist in his circle, admired by the audiences, coveted by managers, ad most of all, a new breathe in the rising competition with the movies industry. From newspapers' reviews, chronicles and advertising, the present article invites the readers to know the trajectory of the Argentinian Norberto Américo Aymonino.

Keywords:

Theatrical revue; Aymond; Transvestism.

\begin{abstract}
Travestido de Sarah Bernhardt, impressionava e divertia. Curiosamente, em 1917, em São João del Rei, Minas Gerais, houve uma montagem do Tintim por Tintim com um elenco exclusivamente masculino. Imaginem isso em 1917! Ficou também popular o caso de Ivaná, um bailarino francês, filho de portugueses, que Walter Pinto transformou em travesti na sua companhia. Estamos tratando agora, porém, do travesti como estrela do espetáculo, ao desviar o apelo erótico da mulher para o homossexual (VENEZIANO, 1991, p. 53).
\end{abstract}

Além de John Bridges, havia também o travestido conhecido como Vigorelli. Já na década de vinte, alguns nomes, mesmo que em pequena escala se comparados a Aymond e Ivaná ${ }^{1}$ também tinham alguns papéis no teatro. Sendo eles: Mirko, Nery, Pierrot, Charmont, Walters e Darwin ${ }^{2}$. Outros nomes como: Derkas, Deny, Sartorelli, Del Musio, Jean Grand, Walter Bank, Ramos, Blandier, Karrerá, Maury Dennys e Pierret ${ }^{3}$ se apresentavam nas décadas de 20, 30 e 40 travestidos em cassinos e cabarés. 
Pouco ou nada se sabe sobre esses artistas. Primeiro porque eles usavam, em sua maioria, pseudônimos, o que dificulta a busca por seus paradeiros; segundo porque foram classificados como artistas de menor porte, então, indignos de serem noticiados nos jornais. Como dito anteriormente, Aymond e Ivaná, foram exceção.

Diante de tal informação, esse artigo busca compilar rastros desse homem que foi fiel à sua arte, mesmo tendo vivido em tempos difíceis, e que levou seu talento para outros destinos como para o Brasil, por exemplo.

A relação de intercâmbio cultural entre as cidades de Buenos Aires e Rio de Janeiro era notadamente muito profícua, uma vez que companhias europeias encontravam dificuldades em chegar ao território americano, especialmente durante a Primeira Guerra Mundial. Posteriormente, essa relação se fortalece ainda mais; é criado o termo "praças artísticas" (VERAS, 2017, p.87). As praças artísticas seriam "espaços onde acordos comerciais entre empresários, artistas e publicitários se expressavam em resposta à demanda do público urbano por diversão e cultura" (VERAS, 2017, p.87). A princípio, cidades como Nova Iorque, Paris, Havana e Buenos Aires faziam parte dessa praça de relações. Mas à frente, Rio de Janeiro, Cidade do México e Santiago do Chile também ingressaram. Como resultado dessa parceria já antiga entre as cidades, Aymond, empregado pela Companhia Argentina de Revistas, aporta no Brasil.

A companhia chega em 1926, e encena a peça AEIOU, que ficou em cartaz cerca de um mês no Rio de Janeiro. Sucesso de público e crítica, a peça alavancou o nome da garganta de ouro, como era conhecido, aos olhos dos empresários brasileiros. O artista encenou também mais duas outras peças com a companhia antes de ser contratado pelo empresário brasileiro Jardel Jércolis. Aymond faria seu nome em solo brasileiro ao lado desse empresário.

\section{AYMOND E A COMPANHIA DE SAINETES E REVISTAS TRO-LO-LÓ}

No ano de 1925 Jardel Jércolis ${ }^{4}$ criou juntamente com José do Patrocínio Filho ${ }^{5}$ a Companhia de Sainetes e Revistas Tro-lo-ló. Companhia formada da junção de ideais de dois jovens recém- chegados da Europa propunha revistas modernas, elegantes, com coreografias bem ensaiadas e cenários luxuosos. Caiu logo nas graças do público carioca. Peças como Fora do Sério, Fla-Flu e Zig-Zag foram alguns dos sucessos de bilheteria emplacados pela companhia. A temporada de Fla-Flu no Rio de Janeiro rendeu a Jardel Jércolis turnê também em São Paulo. Aymond, que já havia terminado sua temporada na Companhia Argentina de Revistas, foi contratado por Jércolis e se juntou à companhia Tro-lo-ló. O jornal 0 Correio Paulistano informou a seus leitores que Aymond após o fim da temporada de Fla-Flu permaneceria em São Paulo, atuando também na peça Zig-Zag. A propaganda jornalística era elemento fundamental na promoção das peças e dos artistas no teatro de revista.

A engrenagem revisteira contava com a visibilidade da imprensa para que seus espetáculos fossem divulgados. O que deveras importava naquele momento era a relação entre artista e público. Os empresários apostavam muito mais no carisma e talento dos atores do que na peça em si. Como recorrentemente salientam pesquisadores do teatro de revista: "o ator tornaria-se o ponto vital na configuração de um sistema teatral brasileiro firmado numa realidade de produção solidamente articulada implantada no século XIX e que se estenderia por todo o século XX" (MEDEIROS, 2002, p.2). O histrionismo presente no ambiente revisteiro tinha em Aymond uma pedra bruta a ser lapidada.

\section{8: O ANO DO SUCESSO}

O Teatro de Revista Brasileiro durou por muitos anos. Graças ao seu caráter polissêmico e a ardileza dos empresários donos das companhias, a história do teatro revisteiro é a história da inovação permanente. Sua hegemonia vivia em constante ameaça frente a outros meios de entretenimento. A disputa pelo domínio do campo cultural (BOURDIEU, 2011) sempre fora uma questão, e era muito importante manter a visibilidade. A fragilidade das companhias era tamanha que, se uma peça fracassasse, todos os empregados poderiam ser prejudicados, ou talvez a companhia sequer conseguisse se reerguer, indo à falência.

Destarte, era imperativo agradar ao público. A engrenagem revisteira apostava muito mais no talento solo de seus artistas; a montagem e a cena acabavam 


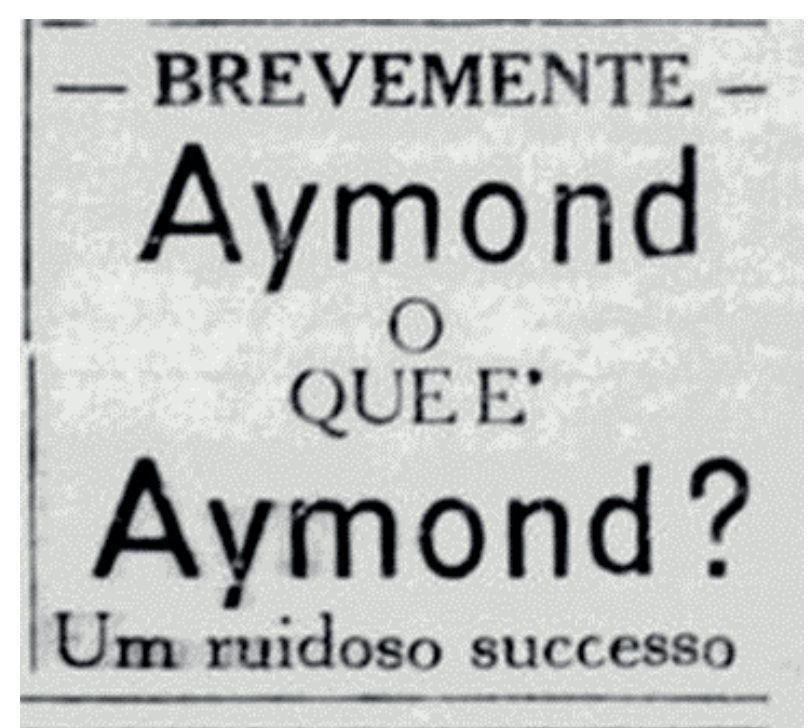

Figura 1 - O Paiz, Rio de Janeiro, 12. ago. 1928. Coluna Artes e Artistas, p.11.

ficando em segundo plano. Veneziano (2004) afirma a importância fundamental do espectador:

\begin{abstract}
Aberta a fenda para o improviso, o ator no teatro de revista deveria, rigorosamente, olhar o público. $\mathrm{E}$, neste momento, que se movia dentro de um bloco dramatúrgico-estrutural fixo, renunciava o modelo fixo, previsto e estabelecido. Os atores se obrigavam a interpretar sobre o público, a escutar os tempos, o ritmo do público, a ouvir o que acontecia, e a improvisar (VENEZIANO, 2004, p. 36).
\end{abstract}

Portanto, a estratégia era cativar o público explorando as relações de quem assistia com quem atuava. Alguns desses laços poderiam ser de admiração, de carinho ou de projeção. Parte da plateia, no entanto, preferia frequentar as peças pela comicidade característica de alguns atores. Já no caso de Aymond, o público experienciava um misto de fascínio, mistério e curiosidade. A propaganda do jornal O Paiz (1928), ilustra a atmosfera de mistério atrelada ao nome do transformista:
No ano de 1928, Aymond se tornou bastante conhecido no circuito revisteiro. Foi nesse ano que Aymond estrelou a peça Palácio das Águias, contracenando ao lado de Alda Garrido ${ }^{6}$, Olympio Bastos ${ }^{7}$ e Vicente Celestino ${ }^{8}$. Dividida em quadros, a história de Palácio das Águias era um misto de humor, romance, viagens e crítica política. Um desses quadros, Palácio das Águias era metáfora para o Palácio do Catete. Já $A$ República em Guerra era sátira ao governo de Washington Luís e de sua política da ordem social atribuída à polícia.

Contudo, não era só de assunto sério que se fazia uma revista. A peça contava também com música de amor, imitações engraçadas, tangos, fados, desfile e personagens-tipo. Aymond se apresentou mais de uma vez durante a peça e encantou com seus números de canto. Sua voz era considerada lindíssima, seu travestimento impecável e seu figurino luxuosíssimo.

A peça ficou em cartaz por mais de um mês, o que demonstra o sucesso da produção, dada a conhecida efemeridade das revistas. Ao compilar alguns dos jornais cariocas durante os anos de 1926 e 1928, nota-se que Aymond foi ganhando mais visibilidade ao longo dos anos. 0 brasileiro estava começando a conhecer cada vez mais o artista, como mostra a tabela abaixo:

É perceptível o aumento da incidência do nome de Aymond nos jornais cariocas; enquanto fora mencionado somente três vezes no jornal $A$ Noite em seu primeiro ano no Brasil, esse número sobe para vinte menções já em 1928. O crescimento pode ser entendido, primeiro, porque Aymond despertou interesse de companhias brasileiras e, dessa maneira, começou a fazer cada vez mais parte do corpo artístico daqui; e, segundo, porque como seu trabalho era incomum, os

\begin{tabular}{ccccc} 
Ano & Correio da Manhã & Gazeta de Notícias & O Paiz & A Noite \\
\hline 1926 & 10 & 17 & 7 & 3 \\
1928 & 27 & 21 & 31 & 20 \\
\hline
\end{tabular}

Tabela 1 - Incidência de vezes em que Aymond aparece nos jornais cariocas nos anos de 1926 e 1928. 
empresários que o contratavam, apostavam em noticiar seu nome como chamariz para aumentar as bilheterias. Afinal, o espectador só poderia conhecer Aymond indo ao teatro assisti-lo.

\section{BRASIL: SUA SEGUNDA CASA}

Aymond, definitivamente, se encantou pelo teatro brasileiro. De acordo com as fontes e os documentos encontrados, o travestido permaneceu se apresentando aqui até mais ou menos 1945. Viajou por diversos estados. Em 1933 atuou em espetáculos no Rio Grande do Sul e Paraná. O travestido foi recebido com muito entusiasmo pelos sulistas. O responsável por noticiar sua chegada à Porto Alegre descreveu o show como sendo "riquíssimo e invulgar" e "perfeito para ser assistido pela sociedade riograndense". Além disso, o redator dedica-se a resumir as passagens de Aymond pelo Uruguai, Chile e sua terra natal, a Argentina. Toda essa estratégia era proposital. Garantia o status de artista internacional de Aymond, e essa era definitivamente uma promoção bastante eficaz.

Em 1934 o transformista voltou para São Paulo, e em 1936 ao Rio de Janeiro. Já em 1938, ele chega a Pernambuco para se apresentar no Grande Hotel. O jornal recifense Diário da Manhã anunciou seus shows. O artista retornou a Pernambuco em 1941 para atuar na V Festa da Mocidade. O jornal Diário da Manhã também noticiou sua volta. A reportagem de 1941 descreveu Aymond da seguinte maneira: "apresenta-se em toillete feminina, que eram lindas roupas femininas. Tem voz de mulher, corpo de mulher, pele de mulher, braços de mulher, pernas de mulher, mas apesar disso tudo, não é mulher é homem" (Diário da Manhã, Pernambuco, 27 de dez, 1941). O jornalista escreve ainda que sua personificação feminina agradava muito nos palcos. Embora o autor da notícia estivesse tentando ser "lisonjeiro" e preocupado em proporcionar um clima de mistério ao show de Aymond, acaba sendo extremamente grosseiro em seu questionamento final: "agora perguntase, no caso de mobilização qual seria a situação de Aymond, o transformista?".

De fato, Aymond lutou contra esse tipo de reações à sua maneira. Seu refinamento possibilitou que ele ocupasse um patamar social diferente em relação a outros travestidos. Exemplo disso é a disparidade dele com a carioca Madame Satã. É claro que a questão vai muito além de seu guardaroupa. Muitos outros fatores determinantes criam um abismo entre esses dois artistas, de qualquer modo, a reflexão que fica é: fora essa matéria no jornal pernambucano, nas fontes não há vestígio de qualquer situação desconfortável, vexatória ou qualquer incidente envolvendo o nome de Norberto Américo Aymonino. Duas hipóteses podem ser levantadas. A primeira é da falta de conservação e fontes que os pesquisadores de teatro notadamente enfrentam; a segunda é de que Aymond prezava por sua imagem refinada e para tanto se preservava também na vida fora de cena.

Outro aspecto que contribuiu para a boa aceitação de Aymond foi o fato de ser contratado por companhias de renome, de ser estrangeiro, branco e, sobretudo, de nunca ter assumido de fato sua homossexualidade. Uma coisa era seu personagem nas ribaltas, outra coisa era afrontar a sociedade nas ruas. Aymond soube entender os códigos sociais. Veras (2017) afirma:

Ele era transformista e imitava a voz de cantoras
de sucesso mundial com tanta perfeição que
recebeu o apelido de "o artista garganta de ouro".
Mesmo coma dualidade desse apelido, que poderia
suscitar piadas de mal gosto, Norberto tinha boa
aceitação junto ao público que reconhecia seu
talento de imitador e impressionava-se com
sua desenvoltura atuando como personagem
feminina. No palco, ele surpreendia tanto por
imitar o timbre das diferentes cantoras como
também por ser homem e ficar irreconhecível ao
se vestir de "mulher". Ele aparentemente nunca
assumiu ser homossexual, e apesar de trabalhar
comotravesti, vestia-se com roupas consideradas
femininas apenas para atuar. Fora do palco usava
"roupas masculinas". Dessa maneira, é possível
sugerir que Aymond mantinha sua vida sexual em
algum sigilo, tentando não chocar o público e ao
mesmo tempo transferindo para sua personagem
parte das demandas de sua identidade de gênero
(VERAS, 2017, p. 273). Aymond pode ter tido relações enquanto esteve no Brasil, até porque morou na Lapa, lugar considerado na época, como afirma (GREEN, 2003) como um dos lugares pertencentes a topografia homoerótica da cidade fluminense, ou até mesmo nas coxias do teatro, mas preferiu a descrição. No periódico $O$ Teatro em Revista de 1939, Aymond posou travestido, como "divette", mas fez questão de ser fotografado também de terno (Figura 2). 


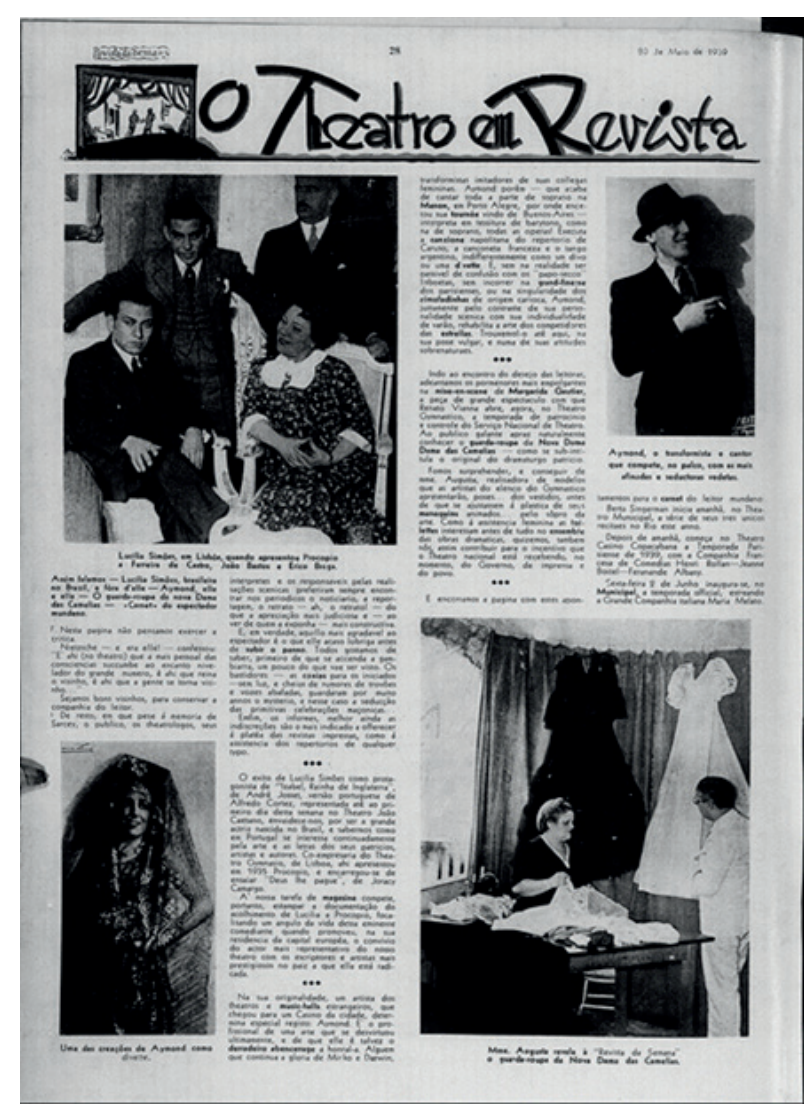

Figura 2 - 0 Teatro em Revista, Rio de Janeiro, 20 de maio. 1933.p.28.

Já entre os anos de 1938 e 1942, mais precisamente em 1941, Aymond se apresentou também em Minas Gerais. Em 1944, retorna ao Rio de Janeiro. Contratado pela Companhia Eva Stachino-Jararaca e Ratinho e já com nome artístico Haymond, o artista contracena com Aracy Cortes $^{9}$ na revista Tudo é Brasil. Revista montada no Teatro Recreio, escrita por Ary Barroso, tem sua estreia em agosto de 1944.

Haymond, agora renovado, se adequa as necessidades do momento. Se torna um travestido mais voltado para o cômico, claro que sem perder o que de mais precioso possuía: sua voz efeminada e seu guarda roupa de luxo. Em 1945 Aymond $^{10}$ é contratado pelo empresário José Ferreira da Silva para performar na peça de Luiz Iglezias e Freire Júnior Que Rei Sou Eu? Montada no Teatro João Caetano, importante espaço da capital federal, Que Rei Sou Eu? definitivamente inseriu o transformista na história do teatro revisteiro brasileiro. Embora não haja quase nenhuma menção do artista na bibliografia que trama do tema, seu nome era noticiado com frequência naquele período da história.
Segundo sua ficha consular de número 139, encontrada no Arquivo Nacional do Rio de Janeiro, Norberto Américo Aymonino ainda permanecia no Brasil aos 51 anos de idade. Seu último contrato, de que se tem notícia, foi em 1945, na Companhia de Ferreira da Silva. Embora constasse em sua profissão artista, não há mais vestígios nos jornais da época de nenhum trabalho do travestido.

\section{AYMOND E SEU GUARDA ROUPA LUXUOSISSÍMO}

O figurino de Aymond foi sempre um dos principais pontos de destaque noticiados pela mídia. Seu guarda roupa todo confeccionado em Paris não era destacado à toa. Apesar do fato de que no começo do século $X X$ a elite estivesse buscando se dissociar do que vinha de fora e lutando por uma identidade nacional, no teatro revisteiro a França ainda era ponto de referência. Segundo Veneziano (1991, p. 52) "embora a revista ao longo do XX começasse a experenciar fórmula própria, ainda sim mantinha estruturas importadas". Ademais, viver em uma cidade como a do Rio de Janeiro do começo do $X X$, era viver em uma cidade movediça, inquieta, em processos de reformas, em obras constantes, com crescimento desordenado.

Assim, o espectador que ia ao teatro esperaria o oposto disso, buscaria o belo e o luxuoso. Não iria ao teatro ver o que já via no seu dia a dia. Exatamente por isso é que os anúncios e as crônicas faziam questão de frisar a riqueza dos cenários e dos figurinos das peças. Segundo Pavis (2010, p.161), "todos os elementos da representação que a análise do espetáculo deseja passar em revista são, por definição, materiais: existem concretamente no palco como materiais, significantes, colocados ali pelos artesãos dos espetáculos". Desse modo, Pavis (2010) evidencia que além da prioridade atribuída a pessoa viva-ator, para a recepção do espetáculo, o espectador vai identificar também outros diferentes sistemas significantes.

Segundo Shetvesona (1993 apud PAVIS 2010), há o hábito no espectador ocidental que os leva primeiro a mencionar a atuação, depois de forma decrescente o cenário, o figurino, a iluminação, a rapidez da execução, a configuração espacial, a coreografia, a música, e a atmosfera. É claro que 
esse padrão não é uma via de regra, de qualquer modo segundo (PAVIS, 2010), o espectador se impressiona primeiramente pelo que é visível e humano e logo em seguida pelo que é material, cenário e figurino.

Os detalhes faziam toda a diferença na corrida pela bilheteria. As companhias tinham plena noção que para competir de igual para igual no circuito revisteiro precisavam investir em autores de nome, atores famosos, em cenografia e em iluminação. Em meio a tantas opções de peças, com as sessões cinematográficas crescendo, exponencialmente, era inteligente gastar um pouco mais em produção para que esse dinheiro fosse recuperado mais tarde.

O guarda roupa cênico de Aymond não era simplesmente um figurino luxuoso. No seu caso, era o portal por onde ele deixava de ser Norberto Américo, um homem, e se tornava qualquer cantora mulher que pudesse ser. Suas roupas eram o primeiro contato que o público tinha antes mesmo dele cantar ou atuar. Era também o elemento estético mais forte nas fotos publicadas nos jornais. Segundo Pavis (2010):

Como todo signo da representação, o figurino é ao mesmo tempo significante (pura materialidade) e significado (elemento integrado a um sistema de sentido). É assim mesmo que Barthes encara o "bom figurino de teatro": ele dever ser material o bastante para significar e transparente o bastante para não constituir seus signos em parasitas..." (PAVIS, 2010, p. 164).

Por fim, Pavis (2010) sintetiza o que ilustra o caso de Aymond, "o figurino é tão vestido pelo corpo quanto o corpo é vestido pelo figurino. 0 ator ajusta sua personagem, afina sua subpartitura ao experimentar seu figurino: um ajuda o outro a encontrar sua identidade" (p.164, 165).

Além do figurino, a maquiagem era outro elemento que somava na criação do personagem "Aymond". A junção da tríade: figurino, maquiagem e voz era o nascimento do travestido. E mais ainda, essa maquiagem era precípua para garantir a ilusão no público. Para Pavis (2010):

Ao interpretar a maquiagem nos esforçamos não apenas para escrever a técnica e o traçado, mas também para compreender como ela modifica e até mesmo constitui o corpo humano e o imaginário ligado a isso. É preciso avaliar a função simbólica que ela preenche num dado momento da espetacularização do corpo (PAVIS, 2010, p. 171).

\section{TIEEATRO RECBEIO}

A's $7 \%$ - HOJE - A's O $\%$

$7^{\circ}$ dia de representacóces da

apparatosa e alegre revista

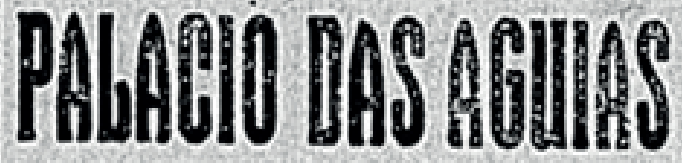

- maior successo

thentral do momento

7)

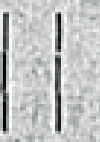

Numeros
bisad

bisados

e trisados

Nunca visto successo de Aymond

- O homem da kargunta maravilhosa

\section{Sempre - PALACIO DAS AGUIAS}

Figura 3 - O Paiz, rio de janeiro, 6 dez .1928. Coluna Artes e Artistas, p.10

\section{O HOMEM DA GARGANTA MARAVILHOSA}

Igualmente imprescindível era sua voz maravilhosa, sua garganta de ouro. O artista consolidou seu status também em função de sua voz. Na promoção publicada no jornal O Paiz (1928) da peça Palácio das Águias, por exemplo, o nome do artista veio em destaque e com o epíteto "o homem da garganta maravilhosa".

Aymond pertencia a tradição já conhecida desde o século XIX de apresentar suas performances musicais durante ou como número final das peças. $O$ teatro era um importante veículo difusor tanto de músicos quanto de músicas, que ao caírem no gosto do público traziam para a peça igualmente promoção. Segundo Mencarelli (2003, p. 33) "os cartazes de divulgação anunciavam os nomes dos espetáculos ao lado dos títulos em negrito das músicas de maior sucesso, o que mostra a importância que estas tinham no contexto das apresentações". Estruturalmente os teatros eram projetados para que a música fosse um elemento chave das apresentações. Como afirma a pesquisadora (REIS, 2019): 
Tendo sido erguidas para acolher uma grande massa de espectador, as espaçosas casas de espetáculos da Praça Tiradentes e arredores, principal polo teatral da cidade desde o século XIX, contavam com amplos palcos e urdimentos elevados, de modo a que os cenários pudessem subir e descer com facilidade, tendo ainda um fosso para a orquestra, indispensável aos espetáculos musicados ( REIS 2019 apud LIMA, 2000, p. 113).

A voz seria, desse modo, o instrumento mais importante do ator. Fosse para declamar, fosse para cantar, saber usar a voz com graça, com assertividade, com afinação, e com boa retórica garantia ao ator destaque dentro do mundo teatral. O travestido cantava todo o tipo de música: tangos, sambas, operetas; e também cantava coplas para introduzir os personagens da peça, além disso, poderia também apresentar chansonettes nos entreatos. A versatilidade do ator revisteiro era uma característica muito presente dentro desse universo e Aymond não fora exceção. Prova disso eram os anúncios em que ele aparecia sendo chamado de "artista gênero Fregoli".

Luigi Leopoldo Fregoli foi considerado um dos artistas mais versáteis de seu tempo. Fregoli era famoso por sua extraordinária habilidade de fazer muitos papeis em um mesmo espetáculo e por sua rapidez ao incorporar esses personagens no palco. O artista italiano atuou em Roma, Genova e Florença. Da Itália, Fregoli partiu para a Argentina, onde morou por um tempo e depois Brasil, Espanha e Estados Unidos.

Fregoli teve seu sobrenome usado para nomear uma síndrome cujo indivíduo apresenta delírios e acredita ter a capacidade de mudar sua aparência ou se disfarçar. Aymond, aos olhos da imprensa, fazia exatamente isso. Disfarçava-se de mulher e conseguia iludir até os mais experientes críticos no palco. Pesquisando sobre a carreira de Aymond aqui no Brasil percebe-se que, embora não tivesse visto permanente, o travestido viveu por muito tempo no país.

No final dos anos 20, com a introdução dos rádios a válvula, a competição com o rádio também se intensificou. O cinema americano, principalmente a Warner Bros, vendia cada vez mais películas mundo afora. O teatro se encontrava em posição delicada. Agora mais do que nunca o investimento em atores talentosos, cenários luxuosos, girls, e histórias interessantes se tornava necessário. Partindo dessa afirmação é que mais uma vez reitera-se o papel importante que Aymond teve nas peças em que atuou. Os homens de teatro estavam preocupados em manter seus negócios e, portanto, lutavam como podiam. Em depoimento, Dercy Gonçalves por exemplo, contou como Jardel Jércolis anunciava seus cenários como inéditos, mas na realidade, os comprava já usados de companhias europeias. O ilusionismo era a palavra-chave no teatro de revista. Proporcionar ao espectador um show satisfatório sem ser tão dispendioso era o objetivo. E quem mais, a não ser Aymond, poderia proporcionar essa ilusão?

\section{CONSIDERAÇÕES FINAIS}

O que esse artigo trouxe foi a importância de um artista que ficou completamente esquecido pela historiografia do teatro de revista. O que esse estudo percebeu pesquisando nos jornais vai além do papel atribuído de homem que se traveste de mulher. Aymond transcendia.

O artista "drag" ao perfomatizar e trazer para o palco qualquer diva que quisesse ser descolava do lugar comum, da caricatura, da paródia. Não à toa que ele agradava ao público. Aymond estava representando o novo, flertava com a modernidade, mas ao mesmo tempo, cantava o antigo e talvez por isso fizesse sucesso.

\section{NOTAS}

01. Em 1953 o grande diretor teatral Walter Pinto, sempre buscando novas atrações internacionais para seus luxuosos espetáculos, anunciou a contratação da vedete portuguesa de nome Ivaná. Vinda das principais casas de espetáculos parisienses, ela fez sua estreia nos palcos brasileiros no espetáculo É Fogo na Jaca.

02. Desconheço qualquer produção acerca desses artistas.

03. Da mesma maneira desconheço qualquer produção sobre qualquer um desses artistas. Os únicos que encontrei menção quando pesquisava por Aymond, foram Karrerá e Jean Grand. O primeiro mencionado em 1925 e o segundo em 1947. 
04. Jardel Jércolis nasceu Jardel Gonzaga de Bôscoli, no dia 13 de outubro de 1894, em São Cristóvão, Rio de Janeiro. Filho de José Ventura Bôscoli e de Cordélia Bôscoli, teve sua estreia profissional em 1912, no Teatro Municipal de Niterói, como ator principal da Companhia Ismênia dos Santos. Faleceu em 19 de fevereiro de 1983, no Rio de Janeiro. Deixou um legado de artistas que se perpetuam até hoje.

05. José Carlos do Patrocínio Filho (18851929), conhecido como Zeca, era filho de José do Patrocínio, o herói da abolição da escravatura. José Carlos do Patrocínio Filho era jornalista e escritor e junto de Jércolis foi responsável pelos primeiros sucessos da Tro-lo-ló.

06. Alda Garrido (1896-1970) foi uma das principais artistas do Teatro de Revista Brasileiro. Atuou em diversas peças, trabalhou com muitos empresários importantes e contracenou ao lado de artistas como Luiz Peixoto, Luiz Iglezias e Freire Júnior. Atuou em peças muito famosas do teatro revisteiro, tais como Da Favela ao Catete, Brasil Pandeiro e Dona Xepa.

07. Olympio Bastos (1902-1956) conhecido como Mesquitinha nasceu em Portugal e mudou-se para o Brasil ainda menino. Mesquitinha foi ator cômico, ensaiador, empresário de teatro e também de rádio e cinema. Seus parceiros mais emblemáticos foram Oscarito, Grande Otelo e Carmen Miranda.

08. Antônio Vicente Filippe Celestino (18941968) aos 26 anos montou uma companhia de operetas, emplacando sucessos como Urubu Subiu. Rapidamente, depois de oportunidade no teatro, alcançou renome. Formou companhias de revistas e operetas com atrizes-cantoras. As excursões pelo Brasil renderam-Ihe muito dinheiro e só fizeram aumentar sua popularidade. Nos anos 20, reinava absoluto como ídolo da canção. Vicente Celestino teve uma das mais longas carreiras entre os cantores brasileiros. Quando morreu, às vésperas dos 74 anos, no Hotel Normandie, em São Paulo, estava de saída para um show com Caetano Veloso e Gilberto Gil, na famosa gafieira "Pérola Negra", que seria gravado para um programa de televisão.

09. De igual maneira à Alda Garrido, Aracy Cortes (1904-1985) foi uma musa de destaque no teatro revisteiro. Atuou em muitas peças, além de ser uma cantora talentosíssima. Foi vizinha e amiga de Pixinguinha. Intérprete do famoso samba Jura, Aracy Cortes foi definitivamente um ícone da cultura brasileira.

10. Mesmo com o acréscimo do " $\mathrm{H}$ " em seu nome, optei por permanecer chamando-o de "Aymond", já que esse nome foi a grafia na qual o ator ficou conhecido na maior parte de sua carreira.

\section{REFERÊNCIAS}

BOURDIEU, Pierre. O Poder Simbólico. São Paulo. Editora Edições 70, 2011.

GREEN, J. N. O Pasquim e Madame Satã, a "rainha" negra da boemia brasileira. Topoi, Rio de Janeiro [online]. 2003, vol.4, n.7, pp.201221.

MEDEIROS, C. J. L. Yan Michalski e a consolidação da crítica moderna carioca no início dos anos 60: a trajetória da crítica no teatro brasileiro. 2002. Dissertação (Mestrado em Teatro). UNIRIO, Rio de Janeiro.

MENCARELLI, F. A voz e a partitura: teatro musical, indústria e diversidade cultural no Rio de Janeiro (1868-1908). São Paulo: Editora da UNICAMP, 2003.

PAVIS, P. A Análise dos Espetáculos. São Paulo: Editora Perspectiva, 2010.

REIS, A.C. Dos edifícios teatrais às ondas do rádio: apontamentos sobre atuação no teatro carioca da primeira metade do século XX. In: V Jornada Nacional Arquitetura, Teatro e Cultura. $\mathrm{n}^{0} .5$, Rio de Janeiro, 2019.

VENEZIANO, N. Revisitando o Baú Revisteiro. 0 Percevejo. RJ: Unirio, ano 12, n. 13, 2004.

VENEZIANO, N. O Teatro de Revista no Brasil: Dramaturgia e convenções. Campinas, SP: Pontes/ Editora da Universidade Estadual de Campinas, 1991.

VERAS, F. R. "Fábricas da alegria": o mercado de diversões e a organização do trabalho artístico no Rio de Janeiro e Buenos Aires (1918-1934). Rio de Janeiro: FGV, 2017. 
SOBRE A AUTORA

Giovanna Zamith Cesário é graduada em Ciências Sociais pela Universidade Federal Fluminense, é graduada em História pela Universidade Federal do Rio de Janeiro. Atualmente aluna do Mestrado em História Social também pela Universidade Federal do Rio de Janeiro. 